\title{
Pengaruh Pemberian Motivasi Terhadap Kinerja Pegawai Di Dinas Ketahanan Pangan Dan Peternakan
}

\author{
${ }^{1}$ Kiki Anggraini, ${ }^{2}$ Azhadi Halomoan, ${ }^{3}$ Randuk Efendi Siregar, ${ }^{4}$ Yuslia Daulay \\ ${ }^{1-4}$ Program Magister Manajemen, Fakultas Ekonomi, Universitas Islam Sumatera Utara \\ Article history \\ Received: 12 Jan 2021 \\ Revised: 25 Feb 2021 \\ Accepted: 06 Mar 2021 \\ *Corresponding Author: \\ Kiki Anggraini, Program \\ Studi Magister Manajemen, \\ Fakultas Ekonomi, \\ Universitas Islam Sumatera \\ Utara \\ Email:

\begin{abstract}
Abstrak: Penting untuk mendorong seseorang untuk mau berprilaku danmelakukan sesuatu yang dipengaruhi oleh dalam diri atau dari lingkungan luar agar dapat memenuhi kebutuhan dan tujuan yang telah ditetapkan. Sehingga dapat dikatakan motivasi sangat perlu diberikan kepada pekerja. Pengumpulan data dalam penelitian ini menggunakan metode kuantitatif. Penelitian ini dilakukan dengan memberikan angket kepada 53 orang responden, setiap responden menjawab 10 pertanyaan. hasil penelitian menunjukkan Variabel pemberian motivasi secara parsial berpengaruh secara signifikan terhadap kinerja pegawai di Dinas Ketahanan Pangan dan Peternakan Provinsi Sumatera Utara

Kata Kunci : Pengaruh, Pemberian Motivasi, Kinerja Pegawai
\end{abstract}

kikianggraini@gmail.com

\section{PENDAHULUAN}

Setiap organisasi atau perusahaan baik pemerintah maupun swasta pada dasarnya merupakan suatu wadah yang menampung berbagai potensi sumber daya manusia untuk bekerja sama. Sehingga program melalui motivasi terhadap pekerja dianggap sangat penting demi terciptanya kinerja yang maksimal. Pentingnya kinerja pegawai dalam melaksanakan program kerja Dinas Ketahanan Pangan dan Peternakan Provinsi Sumatera Utara semakin dirasakan. Dengan adanya motivasi yang baik, maka perilaku nyata yang diperlihatkan oleh pegawai sebagai prestasi kerja yang dihasilkan sesuai dengan peranannya di dalam organisasi (Rivai, 2009). Dengan demikian dapat dikatakan bahwa kinerja adalah prestasi kerja seseorang, baik secara kuantitas maupun secara kualitas.

Pemberian motivasi memberikan pengaruh positif dan signifikan terhadap kinerja pegawai (Ekaputri, 2019 ; Sanjaya, 2018). Sementara itu fenomena yang terjadi di Dinas Ketahanan Pangan dan Peternakan Provinsi Sumatera Utara bahwa masih rendahnya motivasi pegawai dalam bekerja serta peranan atasan dalam memotivasi pegawainya. Sebagaimana diuraikan di atas, maka tujuan yang hendak dicapai dalam penelitian ini yaitu untuk menganalisis Pengaruh pemberian motivasi terhadap kinerja pegawai pegawai di Dinas Ketahanan Pangan dan Peternakan Provinsi Sumatera Utara.

\section{METODE PENELITIAN}

Metode pengumpulan data dalam penelitian ini menggunakan pendekatan kuantitatif. Sebagaimana bahwa pendekatan kuantitatif ini berlandaskan pada filsafat positivisme, digunakan untuk meneliti pada populasi atau sampel tertentu (Sugiyono, 2013). Populasi dalam penelitian ini adalah pegawai di Dinas Ketahanan Pangan dan Peternakan Provinsi Sumatera Utara yang berjumlah 53 orang. Dalam analisa data ini, peneliti akan menganalisis data penelitian secara deskriptif, baik itu data primer maupun data sekunder. 


\section{HASIL DAN PEMBAHASAN}

\section{Skor Angket Variabel Pemberian Motivasi $\left(\mathbf{X}_{2}\right)$}

Dari angket yang diberikan kepada 53 orang responden, setiap responden menjawab 10 pertanyaan. Maka penulis mentabulasi hasil jawaban angket untuk variabel pemberian motivasi, dengan rincian skor pada Tabel 1 dibawah.

Tabel 1. Skor Angket Variabel Pemberian Motivasi

\begin{tabular}{|c|c|c|c|c|c|c|c|c|c|c|c|c|}
\hline \multicolumn{13}{|c|}{$\mathbf{X} 2$} \\
\hline \multirow{3}{*}{ No. } & \multicolumn{12}{|c|}{ ALTERNATIVE JAWABAN } \\
\hline & \multicolumn{2}{|c|}{$\mathbf{a}$} & \multicolumn{2}{|c|}{ B } & \multicolumn{2}{|c|}{ c } & \multicolumn{2}{|r|}{ d } & \multicolumn{2}{|r|}{$\mathbf{e}$} & \multicolumn{2}{|c|}{ Jumlah } \\
\hline & f & $\%$ & $\mathbf{f}$ & $\%$ & $\mathbf{f}$ & $\%$ & $\mathbf{f}$ & $\%$ & $\mathbf{f}$ & $\%$ & $\mathbf{f}$ & $\%$ \\
\hline 1 & 14 & 27,5 & 33 & 64,7 & 4 & 7,8 & 0 & 0,0 & 0 & 0,0 & 51 & 100,0 \\
\hline 2 & 16 & 31,4 & 32 & 62,7 & 3 & 5,9 & 0 & 0,0 & 0 & 0,0 & 51 & 100,0 \\
\hline 3 & 14 & 27,5 & 32 & 62,7 & 5 & 9,8 & 0 & 0,0 & 0 & 0,0 & 51 & 100,0 \\
\hline 4 & 15 & 29,4 & 32 & 62,7 & 4 & 7,8 & 0 & 0,0 & 0 & 0,0 & 51 & 100,0 \\
\hline 5 & 10 & 19,6 & 34 & 66,7 & 7 & 13,7 & 0 & 0,0 & 0 & 0,0 & 51 & 100,0 \\
\hline 6 & 18 & 35,3 & 29 & 56,9 & 4 & 7,8 & 0 & 0,0 & 0 & 0,0 & 51 & 100,0 \\
\hline 7 & 20 & 39,2 & 27 & 52,9 & 4 & 7,8 & 0 & 0,0 & 0 & 0,0 & 51 & 100,0 \\
\hline 8 & 19 & 37,3 & 27 & 52,9 & 5 & 9,8 & 0 & 0,0 & 0 & 0,0 & 51 & 100,0 \\
\hline 9 & 8 & 15,7 & 30 & 58,8 & 13 & 25,5 & 0 & 0,0 & 0 & 0,0 & 51 & 100,0 \\
\hline 10 & 20 & 39,2 & 29 & 56,9 & 2 & 3,9 & 0 & 0,0 & 0 & 0,0 & 51 & 100,0 \\
\hline
\end{tabular}

\section{Uji Validitas}

Berdasarkan Tabel 2. dibawah ini sebagian besar dalam setiap variabel memiliki nilai coreccted item correlation (r-hitung) lebih besar dari r-tabel dan dinyatakan valid. Untuk pernyataan yang tidak valid tidak akan dilanjutkan ke pengujian reliabilitas.

Tabel 2. Hasil Uji Validitas Variabel $\left(\mathrm{X}_{2}\right)$

\begin{tabular}{|c|c|c|c|}
\hline Nomor Soal & r-hitung & r-tabel & Keterangan \\
\hline 1 & 0,435 & 0,276 & Valid \\
\hline 2 & 0,675 & 0,276 & Valid \\
\hline 3 & 0,716 & 0,276 & Valid \\
\hline 4 & 0,752 & 0,276 & Valid \\
\hline 5 & 0,568 & 0,276 & Valid \\
\hline 6 & 0,646 & 0,276 & Valid \\
\hline 7 & 0,649 & 0,276 & Valid \\
\hline 8 & 0,691 & 0,276 & Valid \\
\hline 9 & 0,568 & 0,276 & Valid \\
\hline 10 & 0,419 & 0,276 & Valid \\
\hline
\end{tabular}




\section{Uji Reliabilitas}

Berdasarkan tabel 3. dibawah terlihat bahwa nilai Cronbach Alpha seluruh variabel berkisar antara 0 sampai 1 dan lebih cenderung mendekati angka 1, dengan demikian keseluruhan item dalam instrumen pengukuran dapat kategorikan sangat reliabel.

Tabel 3. Hasil Uji Reliabilitas Variabel

\begin{tabular}{|c|c|c|c|}
\hline Variable & Cronbach's Alpha & N of Items & Reliabilitas Status \\
\hline $\mathrm{X}_{1}$ & 0,889 & 10 & Reliabel \\
\hline $\mathrm{X}_{2}$ & 0,815 & 10 & Reliabel \\
\hline $\mathrm{X}_{3}$ & 0,659 & 9 & Reliabel \\
\hline $\mathrm{Y}_{1}$ & 0,853 & 10 & Reliabel \\
\hline
\end{tabular}

\section{Uji Normalitas}

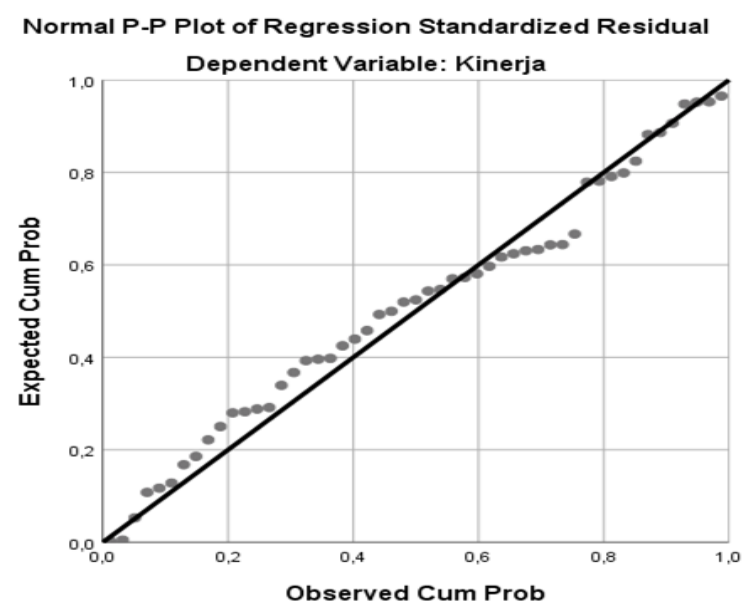

Gambar 1. Normalitas Data

Pada output SPSS seperti gambar dibawah diketahui bagian normal P-P Plot of Regresion Standardized Residual, dapat dijelaskan bahwa data-data (titik-titik) cenderung lurus mengikuti garis diagonal sehingga data dalam penelitian ini cenderung berdistribusi normal.

\section{Uji Multikolinearitas}

Pada ouput SPSS bagian tabel Coefficient diatas, semua angka VIF berada dibawah 5, hal ini menunjukan tidak terjadi multikolinearitas.

Tabel 4. Uji Multikolinearitas

\begin{tabular}{|c|c|c|c|c|c|c|c|}
\hline \multirow{3}{*}{ Model } & \multicolumn{4}{|c|}{ Coefficients $^{a}$} & \multirow{3}{*}{ Sig. } & \multirow{2}{*}{\multicolumn{2}{|c|}{$\begin{array}{l}\text { Collinearity } \\
\text { Statistics }\end{array}$}} \\
\hline & \multicolumn{2}{|c|}{$\begin{array}{c}\text { Unstandardized } \\
\text { Coefficients }\end{array}$} & \multirow{2}{*}{$\begin{array}{c}\text { Standardized } \\
\text { Coefficients } \\
\text { Beta }\end{array}$} & \multirow{2}{*}{$\mathrm{t}$} & & & \\
\hline & B & $\begin{array}{l}\text { Std. } \\
\text { Error }\end{array}$ & & & & Tolerance & VIF \\
\hline (Constant) & 7,271 & 7,737 & & ,940 &, 352 & & \\
\hline Gaya_Kepemimpinan &,- 027 &, 152 &,- 029 &,- 179 & ,859 &, 562 & 1,778 \\
\hline
\end{tabular}




\begin{tabular}{lr|r|r|r|r|r|r}
\hline Pemberian_Motivasi &, 460 &, 178 &, 428 & 2,584 &, 013 &, 538 & $\mathbf{1 , 8 5 7}$ \\
\hline Kompensasi &, 386 &, 176 &, 277 & 2,194 &, 033 &, 930 & $\mathbf{1 , 0 7 5}$ \\
\hline
\end{tabular}

a. Dependent Variable: Kinerja

\section{Uji Heteroskedastisitas}

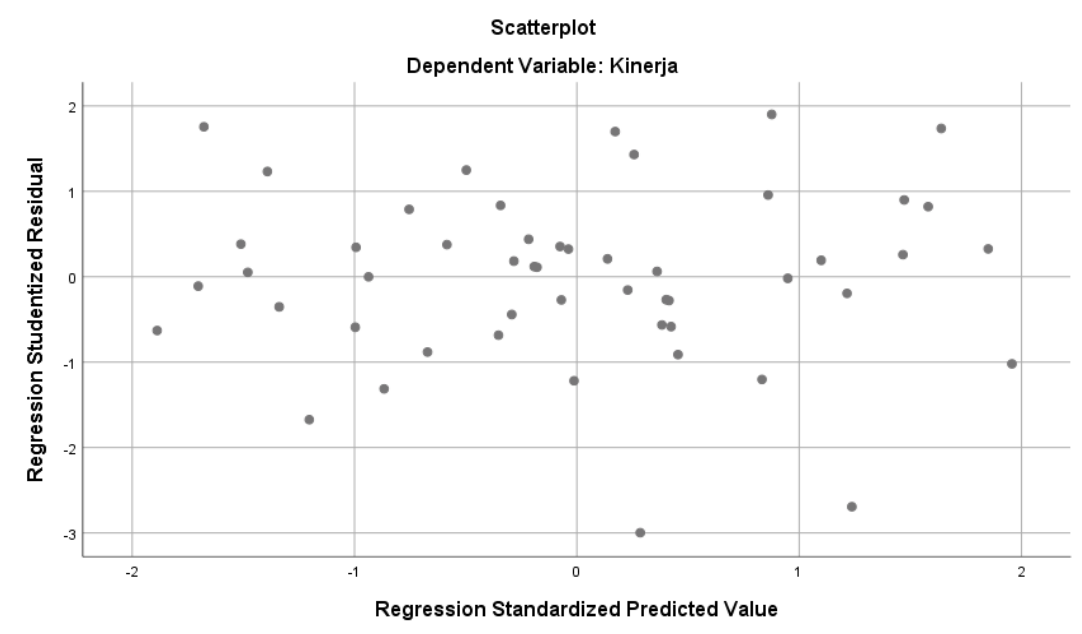

Gambar 2. Uji Heteroskedastitas

Pola Scatterplot seperti pada gambar diatas, terlihat titk-titik menyebar secara acak, tidak membentuk sebuah pola tertentu yang jelas, serta tersebar baik diatas maupun dibawah angka nol pada sumbu Y. Hal ini berarti tidak terjadi heteroskedastisitas pada model regresi, sehingga model regresi layak dipakai.

\section{Analisis Regresi Liniear Berganda}

$$
Y=7,271-0,027 X_{1}+0,460 X_{2}+0,386 X_{3}+\varepsilon
$$

Persamaan diatas dijelaskan bahwa koefesien $\mathrm{X}_{2}$ (pemberian motivasi) memiliki nilai positif yaitu 0,460 . Hal ini menunjukan bahwa variabel pemberian motivasi mempunyai pengaruh positif terhadap kinerja pegawai di Dinas Ketahanan Pangan dan Peternakan Provinsi Sumatera Utara.

\section{Pengujian Simultan (Uji F)}

Tabel 5. Tabel Anova

\begin{tabular}{|c|c|c|c|c|c|c|}
\hline \multicolumn{7}{|c|}{ ANOVA $^{\mathrm{a}}$} \\
\hline Model & & $\begin{array}{l}\text { Sum of } \\
\text { Squares }\end{array}$ & df & Mean Square & $\mathrm{F}$ & Sig. \\
\hline 1 & Regression & 231,587 & 3 & 77,196 & 6,854 &, $001^{\mathrm{b}}$ \\
\hline
\end{tabular}




\begin{tabular}{lr|r|r|l|l}
\hline Residual & 529,393 & 47 & 11,264 & \\
\hline Total & 760,980 & 50 & & \\
\hline
\end{tabular}

a. Dependent Variable: Kinerja

b. Predictors: (Constant), Kompensasi, Gaya_Kepemimpinan, Pemberian_Motivasi

Pada Tabel 5. diatas terlihat bahwa nilai F-hitung adalah 6,854 dan nilai signifikansi 0,001. Dengan derajat bebasnya yaitu $\mathrm{df}_{1}=\mathrm{k}-1=4-1=3$ dan $\mathrm{df}_{2}=\mathrm{N}-\mathrm{k}=51-4=47$, maka nilai F-tabel dengan tingkat kepercayaan $95 \%(\alpha: 0,05)$ adalah $\mathbf{2 , 8 0}$.

Oleh karena itu nilai F-hitung > F-tabel $(6,854>2,80)$ dan dengan nilai signifikansi $0,001<0,05$ maka Ha diterima dan Ho ditolak berarti hipotesis dalam penelitian ini yaitu bahwa pemberian motivasi secara simultan berpengaruh signifikan terhadap kinerja pegawai dalam bekerja di Dinas Ketahanan Pangan dan Peternakan Provinsi Sumatera Utara.

\section{Pengujian Parsial (Uji t)}

Tabel 6. Hasil Uji Parsial Pemberian Motivasi Terhadap Kinerja Pegawai

\section{Coefficients $\mathbf{s}^{\mathrm{a}}$}

\begin{tabular}{|c|c|c|c|c|c|c|c|}
\hline \multirow{2}{*}{ Model } & \multicolumn{2}{|c|}{$\begin{array}{l}\text { Unstandardized } \\
\text { Coefficients }\end{array}$} & \multirow{2}{*}{$\begin{array}{c}\text { Standardized } \\
\text { Coefficients } \\
\text { Beta }\end{array}$} & \multirow{2}{*}{$\mathrm{t}$} & \multirow{2}{*}{ Sig. } & \multicolumn{2}{|c|}{$\begin{array}{l}\text { Collinearity } \\
\text { Statistics }\end{array}$} \\
\hline & B & $\begin{array}{l}\text { Std. } \\
\text { Error }\end{array}$ & & & & Tolerance & VIF \\
\hline Pemberian_Motivasi & , 460 &, 178 & , 428 & 2,584 &, 013 &, 538 & 1,857 \\
\hline
\end{tabular}

a. Dependent Variable: Kinerja

Berdasarkan nilai t-hitung > t-tabel $(2,584>2,012)$, maka dapat disimpulkan Ha diterima dan Ho ditolak, yang artinya variabel pemberian motivasi secara parsial ada pengaruh signifikan terhadap kinerja pegawai di Dinas Ketahanan Pangan dan Peternakan Provinsi Sumatera Utara.

\section{Pengujian Koefisien Determinasi}

Pada Tabel 7. dibawah menunjukan nilai Adjusted $\mathrm{R}^{2}$ adalah $46,0 \%$ variabel kinerja pegawai dalam bekerja di Dinas Ketahanan Pangan dan Peternakan Provinsi Sumatera Utara dapat dijelaskan oleh variabel pemberian motivasi sedangkan sisanya sebesar 54,0\% tidak dilakukan dalam penelitian ini.

Tabel 7. Model Summary

\section{Model Summary}

\begin{tabular}{lr|r|r|r} 
Model & R & \multicolumn{1}{c|}{ R Square } & Adjusted R Square & \multicolumn{1}{c}{ Std. Error of the Estimate } \\
\hline 1 &, $552^{\mathrm{a}}$ &, 304 &, 460 & 3,35614 \\
\hline
\end{tabular}

a. Predictors: (Constant), Kompensasi, Gaya_Kepemimpinan, Pemberian_Motivasi

Sumber: Output SPSS Data Diolah 2020 


\section{KESIMPULAN}

Adapun yang menjadi kesimpulan dari penelitian ini bahwa variabel pemberian motivasi secara parsial ada pengaruh signifikan terhadap kinerja pegawai di Dinas Ketahanan Pangan dan Peternakan Provinsi Sumatera Utara. Sehingga dapat dikatakan bahwa para karyawan sangat butuh suatu motivasi dari atasan. Karena itu akan berdampak pada suatu kinerja yang ingin dicapai oleh suatu organisasi atau perusahaan.

\section{DAFTAR PUSTAKA}

Nadia Yulinda Ekaputri. 2019. Pengaruh Motivasi Terhadap Kinerja Karyawan Dengan Kepuasan Kerja Sebagai Variabel Mediasi.

Rido Sanjaya. 2018. Pengaruh Motivasi Kerja Terhadap Kinerja Pegawai Dalam Perspektif Ekonomi Islam (Studi Di Dinas Sosial Tenaga Kerja dan Transmigrasi Kabupaten Pesisir Barat).

Sugiyono. 2013. Metodelogi Penelitian Kuantitatif, Kualitatif Dan R\&D. Bandung: ALFABETA

Vithzal, Rivai. 2005. Manajemen Sumber Daya Manusia. Jakarta : Raja Grafindo Persada. 